\title{
Solvent Effects on the Electrochemical Behavior of TAPD-Based Redox-Responsive Probes for Cadmium(II)
}

\author{
Rihab Sahli, ${ }^{1,2}$ Janet Bahri, ${ }^{1}$ Issa Tapsoba ${ }^{3}{ }^{\text {Khaled Boujlel, }}{ }^{1}$ and Noureddine Raouafi ${ }^{1}$ \\ ${ }^{1}$ Laboratoire de Chimie Analytique et Electrochimie, Département de Chimie, Faculté des Sciences de Tunis, \\ Université de Tunis El Manar, Campus Universitaire de Tunis El Manar, 2092 Tunis, Tunisia \\ ${ }^{2}$ Laboratoire Méthodes et Techniques d'Analyse, Institut National de Recherche et d'Analyse Physico-Chimique, \\ Biotechpôle de Sidi-Thabet, 2020 Ariana, Tunisia \\ ${ }^{3}$ Laboratoire de Chimie Analytique, Environnement et Bioorganique (LCAEBio), Département de Chimie, UFR/SEA, \\ Université de Ouagadougou, BP 7021, Ouagadougou 03, Burkina Faso
}

Correspondence should be addressed to Rihab Sahli; rihab.sahli@gmail.com

Received 11 July 2014; Accepted 5 October 2014; Published 25 November 2014

Academic Editor: Emmanuel Maisonhaute

Copyright (C) 2014 Rihab Sahli et al. This is an open access article distributed under the Creative Commons Attribution License, which permits unrestricted use, distribution, and reproduction in any medium, provided the original work is properly cited.

\begin{abstract}
Two tetralkylated phenylenediamines (TAPD) 1 and $\mathbf{2}$ have been prepared by reductive alkylation of para-dimethylaminoaniline with furfural or thiophene 2-carboxaldehyde, respectively. Their chelation ability has been evaluated as electrochemical guest-responsive chemosensors for $\mathrm{Cd}(\mathrm{II})$ in acetonitrile $(\mathrm{ACN})$, dimethylformamide (DMF), propylene carbonate (PC), and nitromethane (NM). The voltamperometric studies showed that these compounds are able to bind the Cd(II) cation with strong affinities except in DMF. The redox features of the chemosensors changed drastically when they are bounded to Cd(II) to undergo important anodic potential peak shifts comprised between ca. 500 and ca. $900 \mathrm{mV}$ depending on the solvent. The addition of $\sim 4-$ $10 \%$ molar triflic acid ( $\mathrm{TfOH}$ ) was found to be necessary to achieve rapidly the cation chelation which is slow without the acid. The electrochemical investigations suggested the formation of $1: 2$ stoichiometry complexes $\left[\mathrm{Cd}(\mathbf{L})_{2}\right]^{2+}$. The results are discussed in terms of solvent effects as a competitive electron donating ligand to the cation. The reaction coupling efficiency (RCE) values were determined and were also found to be solvent-dependent.
\end{abstract}

\section{Introduction}

Metallic ions are widely present in the biological systems and play many important roles $[1,2]$. Some others are toxic but are tolerated at low levels such as nickel or cobalt because of their interventions in some biological processes [3]. Other cations can cause major health damage if they are present even in trace amounts such lead(II) and cadmium(II) [4, 5]. Indeed, lead is known to cause saturnism when it is present at high concentration in biological medium [6, 7]. Cadmium has been reported to block calcium channels in sensory neurons and prevents regular central system functioning [8]. Many researchers have been consequently devoted to the development of methods for the determination of these cations.

In living organisms, biological receptors like those found in enzymes or neurons bind selectively to a cation to achieve some goals most of the times in reversible processes. Contrarily, most of the synthetic receptors do not work that way; they tightly bind to cations in nonreversible processes [9]. Only few attempts have been directed at the elaboration of reversible chemosensors useful for the detection and eventually the delivery cations such as calcium ions when they are photochemically or electrochemically triggered $[10,11]$. The first class of chemosensors relies on chromogenic guestresponsive transducers whose properties change when they are linked to cations. The second class of chemosensors depends on reversible electrochemical transducers to achieve the chelation of ions in a chemical reversible manner.

In the last two decades, electroactive chemosensors have been built by using reversible systems. The detection or release of guest ions is monitored through the modification of the electrochemical features of redox centers. For instance, Pearson and Hwang were pioneers in the field and reported many TAPD-based chemosensors formed by crown ethers as ionophore sites and phenylenediamine moiety as a transducer capable of detection of alkaline or alkaline earth 


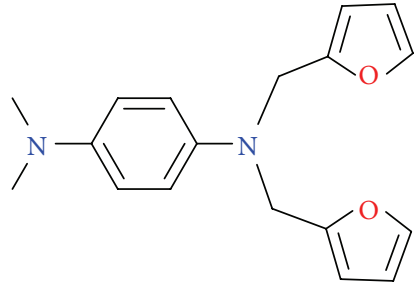

Compound 1

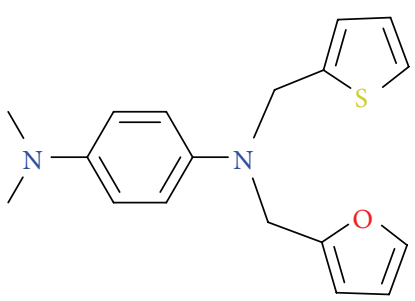

Compound 2

FIgURE 1: Structures of the TAPD-based chemosensors 1 and 2.

cations [12]. In a similar way, Sibert and coworkers prepared chemosensors containing crown thiaethers as hosting sites to selectively recognize noble and heavy-metal ions such as platinum(II) and mercury(II) $[13,14]$. Recently, our group reported the preparation of new chemosensors which are able to chelate metal ions in solution $[15,16]$. Bhattacharyya et al. also recently reported the preparation and the electrochemical study of a novel water-soluble redox active and selective chelator for calcium based on organometallic derivative [17]. Thus, as chelation took place in solution, the thermodynamics and kinetics of the electron transfer are solvent-dependent and so should be the chemosensor electrochemical features prior to and after the cadmium(II) chelation process. For example, Pirson and Huyskens have studied the effect of the solvent in the complexation of same anions and cations by substituted benzoic acid ligands [18]. They concluded that the acetonitrile and nitrobenzene had influence on the stability constants of the formed complexes. Besides, Coetzee and Sharpe reported the interaction between acetonitrile and anions or cations [19]. Moreover, Wang et al. [20] demonstrated the influence of various organic solvents on the electrochemical activity of redox moiety. To our best knowledge there are no reports on the study of complexation dependence on the solvent for TAPD systems. This work is intended to fill in this gap.

The aim of this work is to study the solvent effects on the electrochemical behavior of $\mathbf{1}$ and $\mathbf{2}$ (Figure 1) during the chelation of cadmium(II) following several works devoted to the development of TAPD-based chemosensors for bivalent cations which have been mostly studied in acetonitrile. The electrochemical investigations were conducted by means of cyclic voltammetry $(\mathrm{CV})$ in acetonitrile $(\mathrm{ACN})$, dimethylformamide (DMF), propylene carbonate (PC), or nitromethane (NM), solvents commonly used for electrochemical measurements, aiming to draw some conclusions in the solvent effects on the chemosensors chelating ability.

\section{Materials and Methods}

2.1. Reagents and Chemicals. 4-Dimethylaminoaniline (97\%), sodium cyanoborohydride ( $95 \%)$, sodium bicarbonate $(\geq 95 \%)$, glacial acetic acid $(\geq 99 \%)$, cadmium perchlorate hydrate $\left(\mathrm{Cd}\left(\mathrm{ClO}_{4}\right)_{2} \cdot x \mathrm{H}_{2} \mathrm{O}\right)$, tetrabutylammonium tetrafluoroborate $\left(\mathrm{TBABF}_{4}, \geq 99 \%\right)$, triflic acid $(\geq 99 \%)$, and HPLC grade methanol were purchased from Sigma-Aldrich and used without further purification. Aldehydes (furfural, 99\%, and thiophene-2-carboxaldehyde, 98\%) were freshly distilled before use. PC and NM were purchased from Merck and were distilled and stored in dark; AnhydroScan ACN, DMF, and dichloromethane were purchased, respectively, from LabScan and Sigma-Aldrich and used as received without further purification. A stock solution of cadmium $0.1 \mathrm{M}$ is prepared by dissolving the corresponding amount in acetonitrile.

2.2. Apparatus. Proton and carbon 13 NMR spectra were recorded on a Bruker Avance $300 \mathrm{MHz}$ apparatus in $\mathrm{CDCl}_{3}$. Chemical shifts are given in ppm relative to TMS as internal reference. IR spectra were measured on a Perkin Elmer ATR Alpha spectrophotometer. The electrochemical experiments were conducted in the corresponding solvent containing $0.1 \mathrm{M} \mathrm{TBABF}_{4}$ as supporting electrolyte, at ambient temperature and at a scan rate of $0.1 \mathrm{Vs}^{-1}$. A Radiometer Analytical POL-150 with MED-150 stand-controlled three-electrode glass cell fitted with a carbon glassy disk as a working electrode ( $3 \mathrm{~mm}$-diameters), a platinum wire as a counter electrode, and an SCE (3 M KCl) electrode as a reference electrode was used for the electrochemical measurements. Data acquisition was performed with TraceMaster 5 software for CV experiments and treated using Kaleidagraph 4.0 software package. The working electrode was polished using $0.3 \mu \mathrm{m}$ slurry of alumina at the beginning of each experiment.

\subsection{Preparation and Physicochemical Characterization of} Chemosensors. The compounds were prepared according to published procedure $[15,16]$. The reaction was performed in round bottom flask maintained under argon atmosphere at room temperature and shielded from the light with an aluminum foil. Briefly, compound 1 (2) was obtained by mixing $2.0 \mathrm{mmol}$ of 4 -dimethylaminoaniline, $8.0 \mathrm{mmol}$ of furfural $(4.0 \mathrm{mmol}$ of furfural and $4.0 \mathrm{mmol}$ of thiophene-2carboxaldehyde), and $10.0 \mathrm{mmol}$ of acetic acid in methanol $(50 \mathrm{~mL})$. After $12 \mathrm{~h}$ stirring, $2.0 \mathrm{mmol}$ of sodium cyanoborohydride was added and stirring was kept for a further $4 \mathrm{~h}$. The mixture was quenched with $50 \mathrm{~mL}$ of a saturated sodium bicarbonate solution and extracted twice with $20 \mathrm{~mL}$ of dichloromethane. The organic phase was washed twice with $10 \mathrm{~mL}$ of distilled water, dried over magnesium sulfate, and evaporated to dryness (Scheme 1).

The oily brown residue was purified on silica gel eluted by $30: 70$ ethyl acetate/cyclohexane leading to solid product 


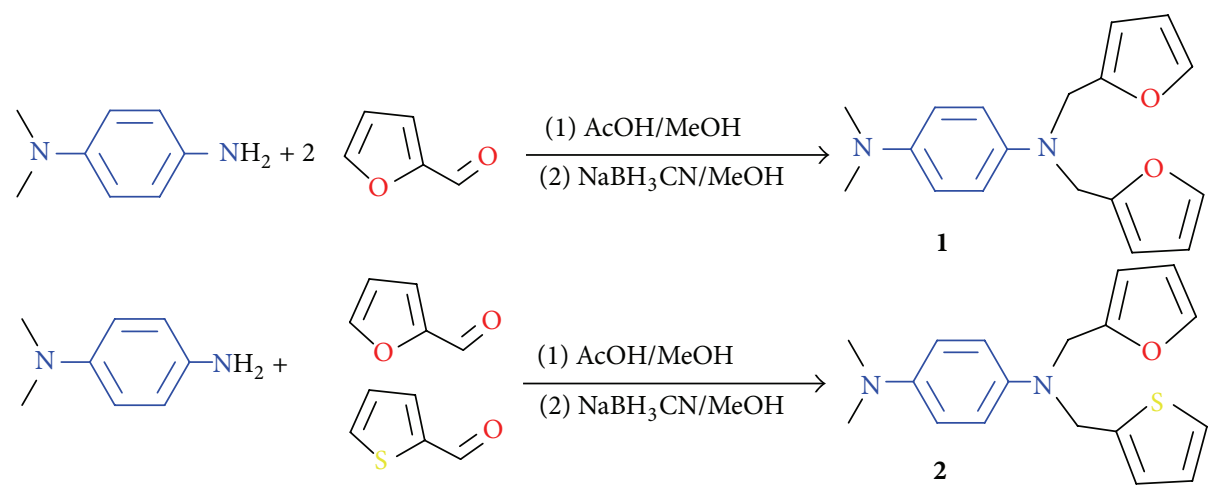

SCHEME 1: Synthetic route to TAPD derivatives via reductive alkylation reaction.

TABLE 1: Thermodynamics data for the first and second peaks: anodic $E_{\mathrm{pa}}$ and cathodic $E_{\mathrm{pc}}$ potential values, peaks separation $\Delta E$, half-wave potential $E_{1 / 2}$, and the current ratio $i_{\mathrm{pc}} / i_{\mathrm{pa}}$ for compounds 1 and 2 measured in ACN, PC, NM, and DMF.

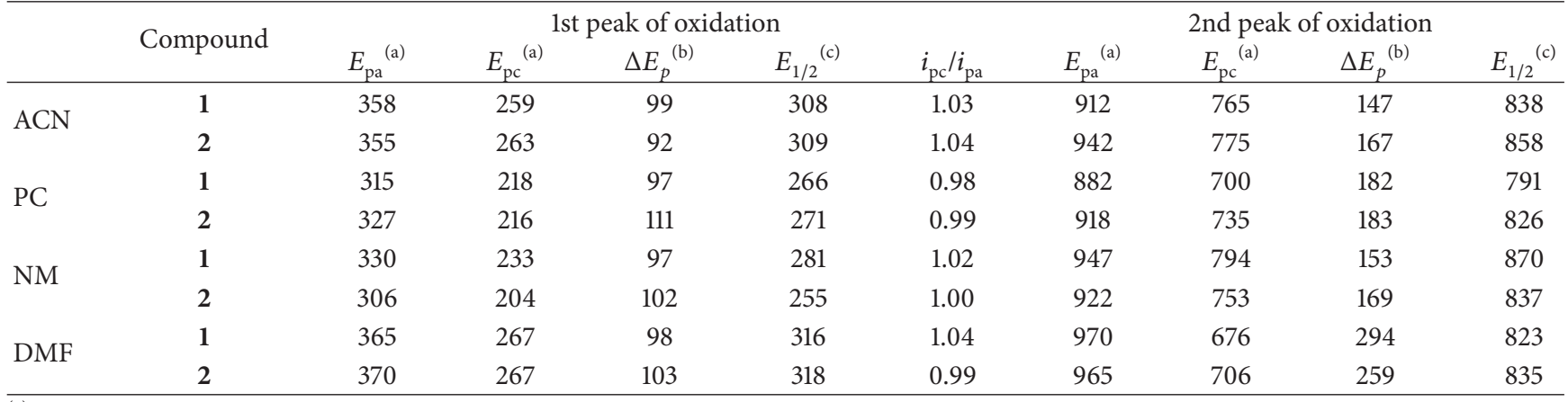

${ }^{(a)} E_{p}$ measured (mV) versus SCE; $E_{\mathrm{pc}}$ are extracted for curves in Figure 2.

(b) $\Delta E_{p}=E_{\mathrm{pa}}-E_{\mathrm{pc}}$.

${ }^{(\mathrm{c})} E_{1 / 2}=E_{\mathrm{pa}}-\Delta E_{p} / 2$.

which was characterized by ${ }^{1} \mathrm{H},{ }^{13} \mathrm{C}$ NMR, and infrared spectroscopy. The characteristics are summarized below.

Compound $1\left(\mathrm{C}_{18} \mathrm{H}_{20} \mathrm{~N}_{2} \mathrm{O}_{2}\right)$ : yield: $61 \%$; mp: $49-51^{\circ} \mathrm{C} ;{ }^{1} \mathrm{H}$ NMR $\left(\mathrm{CDCl}_{3}, 300 \mathrm{MHz}\right) \delta / \mathrm{ppm}: 2.75\left(\mathrm{~s}, 6 \mathrm{H}, \mathrm{CH}_{3}\right), 4.27$ (s, $\left.4 \mathrm{H}, \mathrm{CH}_{2}\right), 6.03\left(\mathrm{~d}, 2 \mathrm{H}\right.$, furan, $\left.{ }^{3} J_{\mathrm{H}-\mathrm{H}}=3 \mathrm{~Hz}\right), 6.19(\mathrm{dd}, 2 \mathrm{H}$, furan, $\left.{ }^{3} J_{\mathrm{H}-\mathrm{H}}=3 \mathrm{~Hz}\right), 6.65\left(\mathrm{~d}, 2 \mathrm{H},{ }^{3} \mathrm{~J}_{\mathrm{H}-\mathrm{H}}=9 \mathrm{~Hz}, \mathrm{CH}_{\text {arom. }}\right.$ ), $6.80\left(\mathrm{~d}, 2 \mathrm{H},{ }^{3} J_{\mathrm{H}-\mathrm{H}}=9 \mathrm{~Hz}, \mathrm{CH}_{\text {arom. }}\right), 7.23$ (s, $2 \mathrm{H}$, furan); ${ }^{13} \mathrm{C}$ NMR ( $\left.\mathrm{CDCl}_{3}, 75.5 \mathrm{MHz}\right) \delta / \mathrm{ppm:} \mathrm{40.7,} \mathrm{47.4,} \mathrm{106.7,} \mathrm{109.1,} \mathrm{113.9,}$ 115.9, 140.2, 140.7, 143.5, 151.6; IR $v_{\max } / \mathrm{cm}^{-1}: 2964(\mathrm{CH}), 2896$ $(\mathrm{CH}), 1514(\mathrm{C}=\mathrm{C}), 1250(\mathrm{C}-\mathrm{N}), 1070(\mathrm{C}-\mathrm{C}), 1056(\mathrm{C}-\mathrm{C}), 810$ (C-O).

Compound $2\left(\mathrm{C}_{18} \mathrm{H}_{20} \mathrm{~N}_{2} \mathrm{OS}\right)$ : yield: $65 \%$; mp: $58-59^{\circ} \mathrm{C}$; ${ }^{1} \mathrm{H}$ NMR $\left(\mathrm{CDCl}_{3}, 300 \mathrm{MHz}\right) \delta / \mathrm{ppm}: 2.77\left(\mathrm{~m}, 6 \mathrm{H}, \mathrm{CH}_{3}\right)$, $4.27\left(\mathrm{~s}, 2 \mathrm{H}, \mathrm{CH}_{2}\right.$, furan), $4.48\left(\mathrm{~s}, 2 \mathrm{H}, \mathrm{CH}_{2}\right.$, thiophene), $6.06\left(\mathrm{~d}, 2 \mathrm{H},{ }^{3} \mathrm{~J}_{\mathrm{H}-\mathrm{H}}=3 \mathrm{~Hz}\right.$, furan), $6.21\left(\mathrm{~d}, 2 \mathrm{H},{ }^{3} J_{\mathrm{H}-\mathrm{H}}=3 \mathrm{~Hz}\right.$, furan), $6.65\left(\mathrm{~d}, 2 \mathrm{H},{ }^{3} J_{\mathrm{H}-\mathrm{H}}=10 \mathrm{~Hz}, \mathrm{CH}_{\text {arom. }}\right), 6.80(\mathrm{~d}, 2 \mathrm{H}$, $\left.{ }^{3} J_{\mathrm{H}-\mathrm{H}}=10 \mathrm{~Hz}, \mathrm{CH}_{\text {arom. }}\right), 7.08\left(\mathrm{~d}, 1 \mathrm{H},{ }^{3} \mathrm{~J}_{\mathrm{H}-\mathrm{H}}=2 \mathrm{~Hz}, \mathrm{CH}_{\text {arom. }}\right.$ ), 7.17 (s, $1 \mathrm{H}$, furan), $7.17\left(\mathrm{~m}, 1 \mathrm{H}\right.$, furan); ${ }^{13} \mathrm{C} \mathrm{NMR}\left(\mathrm{CDCl}_{3}\right.$, $75.1 \mathrm{MHz}) \delta / \mathrm{ppm}: 41.8,48.2,50.7,107.9,110.2,114.9,117.3$, 124.4, 125.2, 126.5, 141.0, 141.8; $v_{\max } / \mathrm{cm}^{-1}$ : IR3663 (CH), 2972 (CH), $1514(\mathrm{C}=\mathrm{C}), 1393(\mathrm{C}-\mathrm{N}), 1248(\mathrm{C}-\mathrm{C}), 809(\mathrm{C}-\mathrm{O}), 720$ (C-S).

\section{Results and Discussion}

3.1. Electrochemistry of the Uncoordinated Chemosensors. $\mathrm{CVs}$ of $\mathbf{1}$ and $\mathbf{2}$ investigated in the different solvents except in DMF exhibit two oxidation peaks. This electrochemical behavior is similar to that reported for tetramethylated para-phenylenediamine (TMPD) [21] which is generally attributed, respectively, to the formation of a TAPD ${ }^{\circ+}$ radicalcation and $\mathrm{TAPD}^{2+}$ (Figures 2(a) and 2(b)).

When the potential reverse sweep is poised to approximately $0.5 \mathrm{~V}$, the first monoelectronic peak is reversible (Figure 3) and this is due to the stability of the generated radical-cation allowing more accurate determination of $i_{\mathrm{pc}}$. The second oxidation peak is irreversible probably due to the deactivation of the generated dication, which is highly reactive, by the nucleophilic impurities present in the medium. In DMF, this peak involves also the oxidation of furan and/or thiophene ring. Table 1 summarized the thermodynamic data of compounds 1 and 2. As it appears in this table, one can observe that the $i_{\mathrm{pc}} / i_{\mathrm{pa}}$ ratio is close to the unity confirming the reversibility of the electron transfer of the first peak [22]. Moreover, at the same concentration, the intensity of the oxidation peak current for compound $\mathbf{1}$ and compound $\mathbf{2}$ decreases from ACN to PC. These results, in agreement 


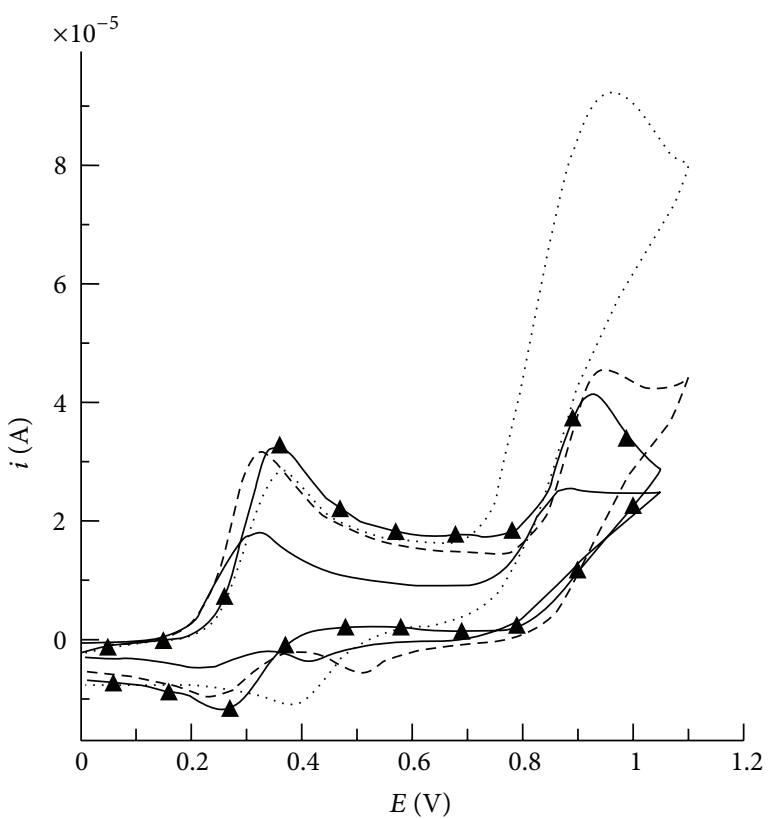

(a)

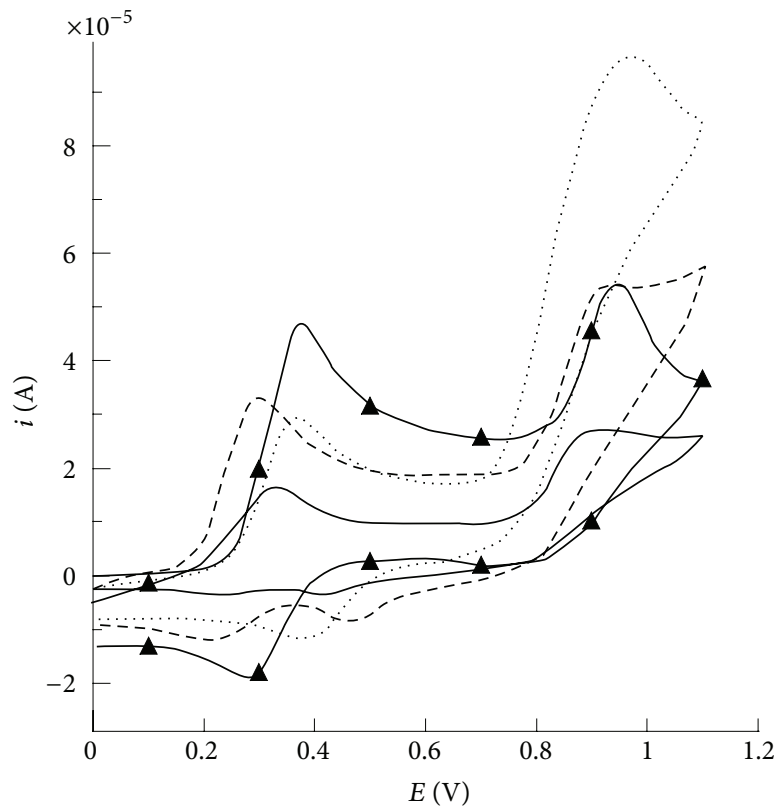

(b)

FIGURE 2: CVs showing the first and second oxidation stages of $\mathbf{1}$ (a) and $\mathbf{2}$ (b) at $2.0 \mathrm{mM}$ concentration; the curves were recorded in ACN $(-\boldsymbol{\Delta})$, in DMF $(\bullet \bullet)$, in NM $(---)$, and in PC $(-)$ containing $0.1 \mathrm{M} \mathrm{TBABF}_{4}$. Working electrode: glassy carbon $(\Phi=3 \mathrm{~mm})$; reference electrode: $\mathrm{SCE}(\mathrm{KCl} 3 \mathrm{M})$; scan rate: $0.1 \mathrm{Vs}^{-1}$.

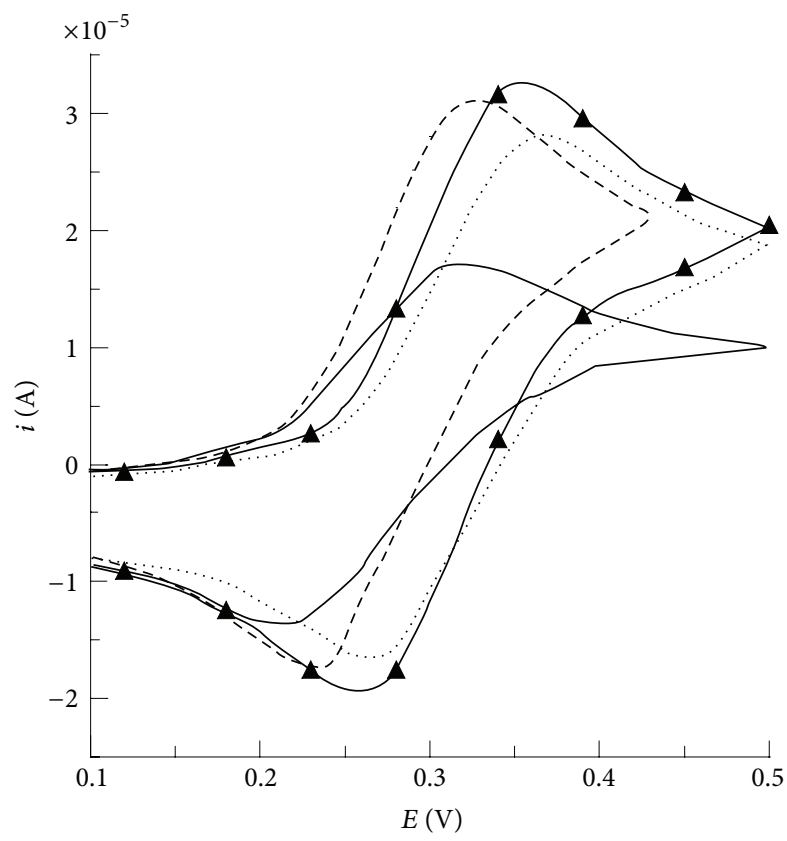

(a)

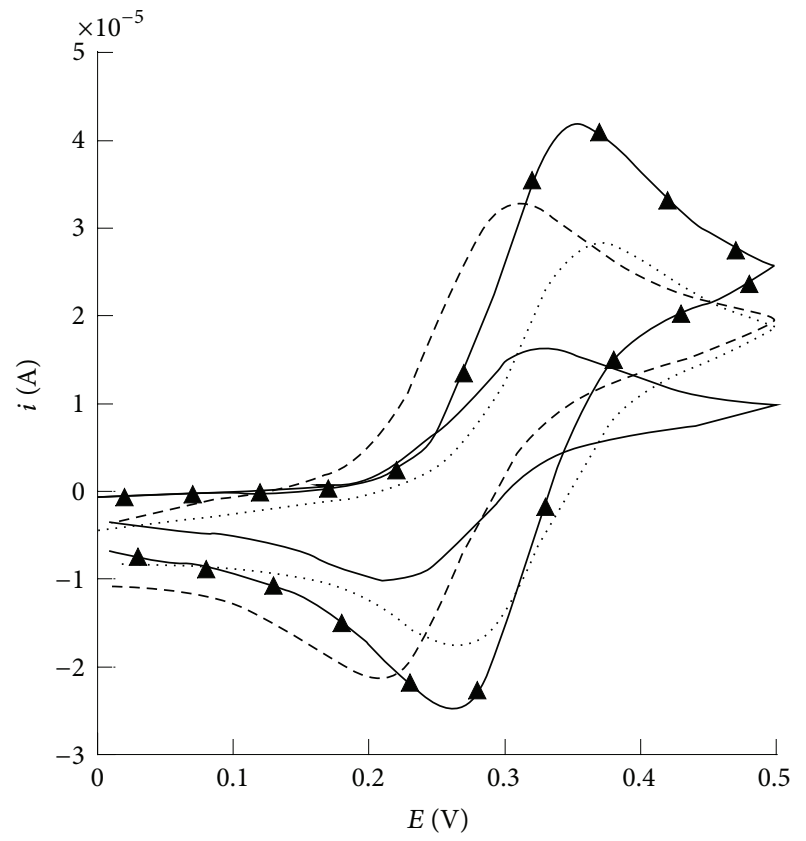

(b)

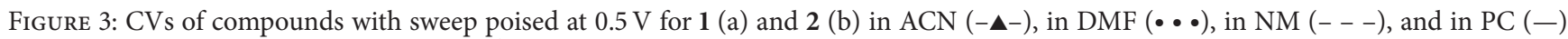
containing $0.1 \mathrm{M} \mathrm{TBABF}_{4}$, scan rate: $0.1 \mathrm{Vs}^{-1}$. Working electrode: glassy carbon; reference electrode: $\mathrm{SCE}(\mathrm{KCl} 3 \mathrm{M})$; concentration: $2.0 \mathrm{mM}$.

with those reported in the literature, could be explained by using the Randles-Sevcik and Stokes-Einstein equations which correlate the peak current upon the solvent viscosity $[23,24]$. Thus, viscosity increase from ACN to PC leads to a decrease in the intensity of the peak current. Moreover, the current intensity is dependent on the diffusion coefficient of the compounds in each solvent which could explain the changes in current intensities [25].

Additionally, one can see in Table 1 that the oxidation potential peaks of the two compounds also depend on the 


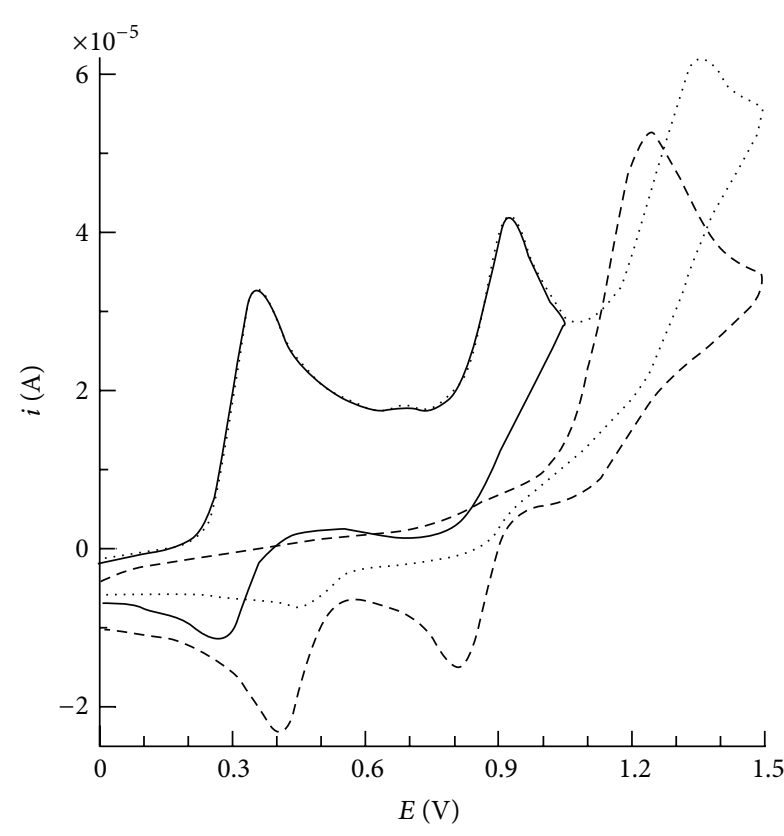

(a)

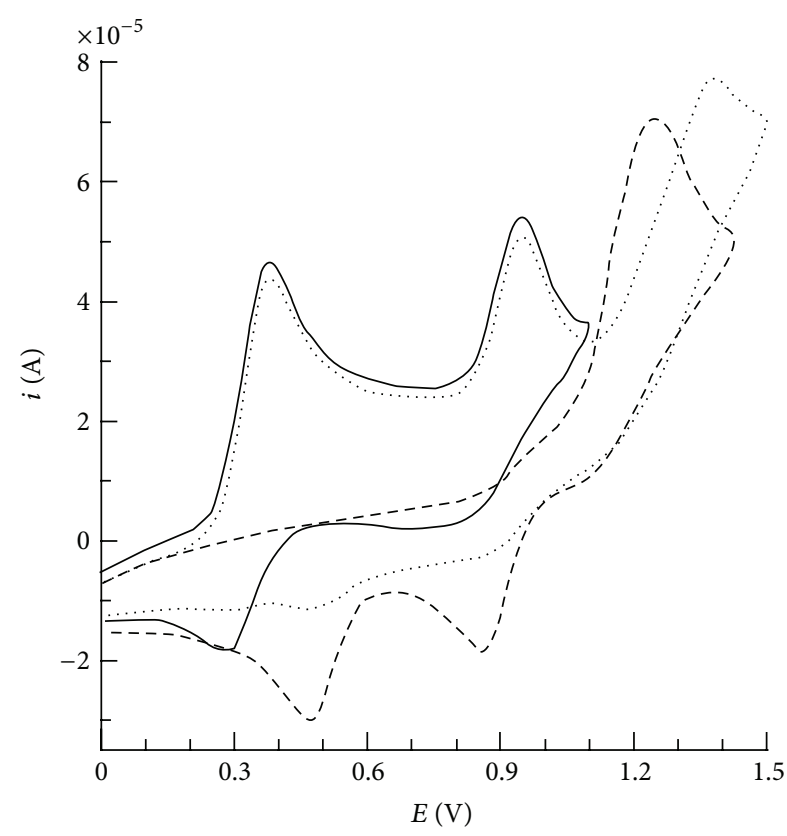

(b)

FIGURE 4: (a) CV curves of $2.0 \mathrm{mM}$ of chemosensor $\mathbf{1}$ in absence (-: inversion potential $E_{i}=1 \mathrm{~V} ; \bullet \cdot \bullet:$ inversion potential $\left.E_{i}=1.5 \mathrm{~V}\right)$ and in presence of $1.0 \mathrm{mM}$ of $\mathrm{Cd}^{2+}(---)$. (b) CV curves of $2.0 \mathrm{mM}$ of chemosensor 2 in absence (-: inversion potential $E_{i}=1 \mathrm{~V}$; $\bullet \bullet \cdot$ : inversion potential $\left.E_{i}=1.5 \mathrm{~V}\right)$ and in presence of 0.5 equivalent of $\mathrm{Cd}^{2+}(---)$. Voltammograms were recorded in $\mathrm{ACN}^{-}$containing $0.1 \mathrm{M} \mathrm{TBABF}_{4}$ as supporting electrolyte. Working electrode: glassy carbon; reference electrode: $\mathrm{SCE}(\mathrm{KCl} 3 \mathrm{M})$; scan rate: $0.1 \mathrm{Vs}^{-1}$.

solvent in which the studies were carried out. For instance, in the case of 1 (2), the difference of the oxidation peak potentials which could be observed comparatively in any two different solvents is at most $40 \mathrm{mV}(50 \mathrm{mV})$. However, one can note that compounds $\mathbf{1}$ and $\mathbf{2}$ can be more easily oxidized in NM and PC than in ACN or DMF. Thus, the oxidation potential is close to $358 \mathrm{mV}$ for compound $\mathbf{1}$ in $\mathrm{ACN}$ while in PC it is only $315 \mathrm{mV}$. This behavior could be due to donoracceptor interaction between the studied components and the solvent [26]. Participation of liquid junction potential could be involved. For any couple of these solvents it is comprised between 0 and $10 \mathrm{mV}$ [27].

The study of the scan rate effect carried out on the first oxidation peak shows that the current intensity increases with the scan rate in the range of $0.05-0.5 \mathrm{Vs}^{-1}$. The linear plot of the logarithm of the first peak current as a function of logarithm of scan rate is close to 0.5 indicating a diffusioncontrolled electron reaction [28].

\subsection{Electrochemistry of the Chemosensors in Presence of Cad-} mium. CVs recorded in presence of 0.5 equivalent of $\mathrm{Cd}(\mathrm{II})$ show that chemosensors are capable of binding to this ion except in DMF. Indeed, it is noticeable on the curves of Figures $4(\mathrm{a})$ and 4 (b) that the addition of 0.5 equivalent of $\mathrm{Cd}(\mathrm{II})$ leads to a total disappearance of the two oxidation peaks characteristic of the uncoordinated chemosensors. This behavior corresponds mostly to a chemical interaction in solution between chemosensors and $\mathrm{Cd}(\mathrm{II})$ as it has been previously reported [12-17]. Indeed, after the addition of cadmium cation, the lone pair of electrons on the nitrogen is involved in the complexation reaction with the metal leading to the disappearance of the two oxidation peaks and a new one is observed at more anodic potential which is different from that of the aromatic ring of thiophene or furan. In our point of view and in comparison with works reported by Amatore group $[11,17]$ and Sahli et al. $[15,16]$, this peak is probably due to the oxidation of the complex 1-Cd(II) or 2-Cd(II). When the scanning is realized at more anodic potential in absence of Cd(II), one can observe a different oxidation peak, which is irreversible, corresponding to the oxidation of furan or thiophene ring (dotted voltammograms) $[29,30]$.

Additionally, temporal monitoring of the $\mathrm{Cd}(\mathrm{II})$ chelation reaction of the chemosensors revealed that the reaction is slow leading to complete disappearance of the chemosensors' signals after $45-60 \mathrm{~min}$ even if 1.0 equivalent of $\mathrm{Cd}(\mathrm{II})$ is added. When 4 to $10 \%$ molar TfOH is added, this cation chelation is accelerated and a purple coloration of the solution is noticed. On the other hand, one can observe that the addition of small amounts of TfOH does not affect the electrochemical features of the chemosensors (figure not shown); since TfOH is a weak acid in organic solvents $\left(\mathrm{pK}_{\mathrm{a}}=0.7\right.$ in ACN) [31], the protonated amounts of $\mathbf{1}$ and $\mathbf{2}$ should remain very low and the oxidation currents are unaltered. Besides, the addition of an increasing quantity of acid (up to 20\%) does not affect the electrochemical behavior of TAPD compounds, nor are the potentials or the currents of the peaks altered. The presence of the acid seems indeed to be necessary to achieve rapidly the complexation reaction. One can hypothesize that the protons from $\mathrm{TfOH}$ protonate the aromatic nitrogen bearing the 


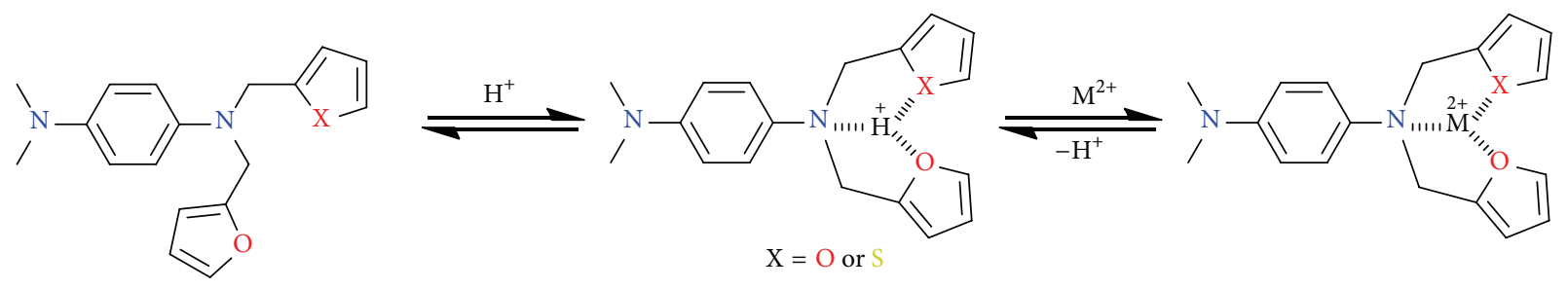

SCHEME 2: Conformational changes of the chemosensors by protonation followed by proton-cation exchange reaction.

two other chelating rings inducing a conformational change, which is thermodynamically unfavoured, followed by a proton-metal exchange giving more rapidly the $\left[\mathrm{Cd}(\mathbf{L})_{2}\right]^{2+}$ complexes. In both cases, at least a nitrogen atom is protonated (Scheme 2) [32].

During the reverse scan, two cathodic peaks are visible in $\mathrm{ACN}, \mathrm{NM}$, or PC corresponding to the two-stage reduction of dication peaks. Indeed, due to the positive charges on compounds $\mathbf{1}$ and $\mathbf{2}$ after the anodic electron transfer, one can suggest the release of $\mathrm{Cd}$ (II) in solution from the inner sphere of the complex by electrostatic repulsion between the positive charges on the phenylenediamine moiety and on $\mathrm{Cd}(\mathrm{II})$ leading to $\mathbf{1}^{2+}$ and $2^{2+}$ which are reducible during the reverse potential scan. The dication reduction gives radical-cation $\mathbf{1}^{\bullet+}$ or $2^{\bullet+}$ leading to neutral species after a second electron transfer. Moreover, the reduction of $\mathbf{1}^{\bullet+} / 2^{\bullet+}$ into the neutral form occurs at higher potentials than of the uncoordinated chemosensors because the recomplexation reaction displaces the interfacial equilibrium, facilitating thus the electron transfer [33]. The chelating abilities of the chemosensors are thus restored. Furthermore, the cathodic current increase may be due to the introduction of perchlorate ions; that is, cadmium perchlorate was used, having a more stabilizing effect on the organic dication than tetrafluoroborate from the supporting electrolyte. On the other hand, the gradual addition of $\mathrm{Cd}$ (II) to solutions of the chemosensors showed that the current of the two oxidation peaks of ligand dropped gradually and completely vanished when 0.5 equivalent of the cation is added suggesting a total complexation of the ligands so it can be concluded that the complex stoichiometry is $1: 2$.

When the chelation of $\mathrm{Cd}(\mathrm{II})$ by the chemosensors is attempted in DMF (Figure 5), the voltammetric curves showed a decreasing of the current intensity and exhibited also a slight shift of oxidation peak potential in the presence of 0.5 equivalent of $\mathrm{Cd}(\mathrm{II})$ toward anodic value suggesting a chemosensor-cation interaction and a solvent-cation interaction, respectively. These interactions remain weak even when 1.0 equivalent of $\mathrm{Cd}(\mathrm{II})$ is added. These relatively weak potential shifts (125 mV for 1 and $48 \mathrm{mV}$ for 2) suggest a possible competition between the ligand and DMF which is a good electron-donating ligand for $\mathrm{Cd}(\mathrm{II})$. This behavior is in agreement with the studies by Jorge and Stradiotto [34], who reported that DMF is able to complex $\mathrm{Sn}$ (II) by removal of ACN molecules. The addition of a small amount of acid to the Cd/ligand in DMF solution does not improve the complexation process.

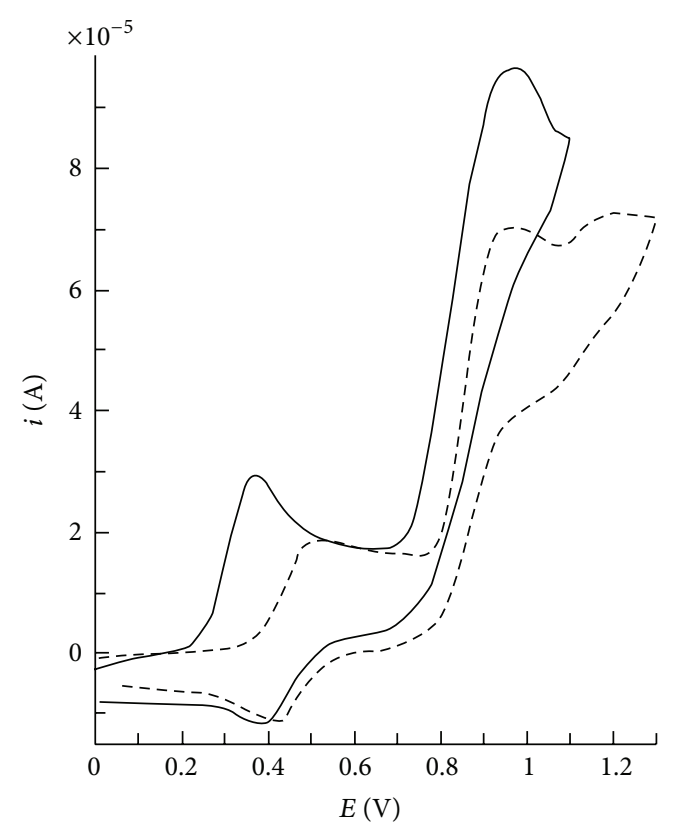

Figure 5: CV of $2.0 \mathrm{mM}$ of chemosensor 1 in absence $(-)$ and in presence of 1.0 equivalent $\mathrm{Cd}^{2+}(2.0 \mathrm{mM})\left(--_{-}\right)$recorded in DMF containing $0.1 \mathrm{M} \mathrm{TBABF}_{4}$. Working electrode: glassy carbon; reference electrode: $\mathrm{SCE}(\mathrm{KCl} 3 \mathrm{M})$; scan rate: $0.1 \mathrm{Vs}^{-1}$.

3.3. Reaction Coupling Efficiency. Depending on the solvent and the chemosensor, potentials of the first oxidation peak of ligands $\mathbf{1}$ and $\mathbf{2}$ and the one corresponding to the complex oxidation are reported in Table 2. As shown in Table 2, one can remark that except in DMF the shift of the potential after the complexation varies from ca. 500 to ca. $900 \mathrm{mV}$ and can be correlated to the stability of the formed complex. These observations are in agreement with works of Beer et al. showing that the stability of the complexes is proportional to the shifts of oxidation potentials of various ferrocenebased ligands [35]. Due to the difficulty of determining $E_{1 / 2}^{3}$ since the third peak is irreversible, the values of $\Delta E_{1 / 2}=$ $E_{1 / 2}^{3}-E_{1 / 2}^{1}$ should stay very close to $\Delta E_{p}=E_{p}^{3}-E_{p}^{1}$ as it is for the first and the second peaks for both compounds. Indeed, the peak potential depends on the electron transfer rate constant and following chemical reactions [36]. This system is considered electrochemically reversible at $0.1 \mathrm{~V} / \mathrm{s}$. This is demonstrated by a low peak to peak separation (less 
TABLE 2: Potentials of first oxidation peak, $E_{p}^{1}$, and complex oxidation peak $E_{p}^{3}, \Delta E$, and the logarithm of the reaction coupling efficiency $(\log \mathrm{RCE})$ for compounds $\mathbf{1}$ and 2 in the presence of 0.5 equivalent of $\mathrm{Cd}^{2+}$ in $\mathrm{ACN}, \mathrm{NM}, \mathrm{PC}$, and DMF containing $0.1 \mathrm{M}$ $\mathrm{TBABF}_{4}$

\begin{tabular}{lcccc}
\hline & $E_{p}^{1^{(\mathrm{a})}}$ & $E_{p}^{3^{(\mathrm{a})}}$ & $\Delta E^{(\mathrm{b})}$ & $-\log \mathrm{RCE}^{(\mathrm{c})}$ \\
\hline $\mathbf{1}$ & 353 & 1247 & $\mathrm{ACN}$ & 14.9 \\
$\mathbf{2}$ & 312 & 118 & -894 & 14.4 \\
\hline & & \multicolumn{3}{c}{$\mathrm{NM}$} \\
$\mathbf{1}$ & 330 & 1218 & -888 & 14.8 \\
$\mathbf{2}$ & 306 & 1094 & -788 & 13.1 \\
\hline & & & $\mathrm{PC}$ & \\
$\mathbf{1}$ & 315 & 1188 & -873 & 14.6 \\
$\mathbf{2}$ & 327 & 884 & -502 & 8.4 \\
\hline
\end{tabular}

${ }^{(\mathrm{a})} E_{p}$ measured $(\mathrm{mV})$ versus SCE.

(b) $\Delta E=E_{p}^{1}-E_{p}^{3}$.

(c) $\log \mathrm{RCE}=\Delta E / 60$.

than $111 \mathrm{mV})$. Degradation rate after the second electron transfer was not determined precisely so $\Delta E_{1 / 2}$ cannot be deduced directly from $\Delta E_{p}$. However, we can infer that $\Delta E_{1 / 2}$ is equal to $\Delta E_{p}$ since the oxidation potential is lowered when chemical reaction displaces the electrochemical equilibrium.

Since the $E_{p}^{3}$ peak of oxidation corresponds to the oxidation of the complexes $\left[\mathrm{Cd}(\mathbf{L})_{2}\right]^{2+}(\mathbf{L}=\mathbf{1}$ or 2$)$, to the radicalcation and subsequent dissociation of the radical-cation complex $\left[\mathrm{Cd}\left(\mathbf{L}^{\bullet}\right)_{2}\right]^{2+}$ into $\mathrm{Cd}(\mathrm{II})$ and free oxidized forms of 1 or 2 , due to the electrostatic repulsion between these two positively charged species $[15,16]$. At this potential, the released radical-cation undergoes a second one-electron transfer to its dication according to Scheme 3.

Beer and coworkers described the reaction coupling efficiency (RCE) as the ratio of $K_{\mathrm{ox}} / K_{\text {red }}$ which are, respectively, the complex stability constants for a given ligand in its oxidized and reduced forms. The RCE can be easily determined from corresponding difference between the oxidation potentials of the uncoordinated and coordinated host and is a very useful tool to evaluate and compare the redox-active ligands efficiency toward metal chelation. This relation can be reasonably applied to determine the RCE [35-37] since oneelectron exchange is sufficient for the dissociation of the complex as previously reported in the case of ferrocene-based chemosensors [38-40]. Very high values of RCE imply that the reaction is complete, which is observed for $\mathrm{ACN}, \mathrm{NM}$, and $\mathrm{PC}$ and not chelation attempted in DMF. In addition, on can note through this table and the results obtained from cyclic voltammetry investigations that chemosensor 1 binds more efficiently to cadmium than chemosensor 2 , probably because compound 1 has two more donating sites than one sulfur and one oxygen atoms in compound 2.

\section{Conclusions}

Cyclic voltammetry of two new chemosensors investigated in $\mathrm{ACN}, \mathrm{NM}, \mathrm{PC}$, and DMF showed that these compounds

$$
\begin{aligned}
& {\left[\mathrm{Cd}(\mathrm{L})_{2}\right](\mathrm{II}) } \frac{-2 e}{\text { at } E_{p}^{3}} \longrightarrow\left[\mathrm{Cd}\left(\mathrm{L}^{*}\right)_{2}\right]^{2+} \\
& {\left[\mathrm{Cd}\left(\mathrm{L}^{\bullet}\right)_{2}\right]^{2+} } \stackrel{ }{\longrightarrow} 2 \mathrm{~L}^{{ }^{++}}+\mathrm{Cd}(\mathrm{II}) \\
& 2 \mathrm{~L}^{\cdot+} \stackrel{-2 e}{\text { at } E_{p}^{3}} 2 \mathrm{~L}^{2+}
\end{aligned}
$$

Scheme 3: Oxidation of the complexes $\left[\mathrm{Cd}(\mathbf{L})_{2}\right]^{2+}$ and their dissociation at the oxidation potential $E_{p}^{3}$.

exhibit two oxidation waves corresponding to a 2-electron transfer from the phenylenediamine moiety. It was also demonstrated using CV that these compounds constituted good ligands for cadmium(II) in solution and the affinity toward this metal depends strongly of the nature of solvent used, and complexes were formed in 1:2 stoichiometry. Moreover, it was shown that this complexation reaction starts after 45 to $60 \mathrm{~min}$ under open circuit conditions due to electrogenerated protons but it can be tremendously accelerated by addition of catalytic amount of TfOH. RCE values showed that ligand binds tightly to the cation except in DMF and the complexes are more stable with ligand $\mathbf{1}$ than with 2 .

\section{Conflict of Interests}

The authors declare that there is no conflict of interests regarding the publication of this paper.

\section{Acknowledgments}

The authors gratefully acknowledge the MHESR for the financial support through LR99ES15 program and the African Network of Electroanalytical Chemists ANEC/ISP for the strengthening south to south scientific collaboration. Issa Tapsoba would like to acknowledge TWAS, the Academy of Sciences for the Developing World, for the support provided by TWAS Visiting Scientist Program.

\section{References}

[1] H. Sigel and A. Siegel, Metal Ions in Biological System: Compendium on Magnesium and Its Role in Biology, Nutrition, and Physiology, vol. 26, Marcel Dekker, New York, NY, USA, 1990.

[2] H. Sigel and A. Siegel, Metal Ions in Biological Systems: Volume 15: Zinc and Its Role in Biology and Nutrition, Marcel Dekker, New York, NY, USA, 1983.

[3] H. Sigel and A. Siegel, Metal Ions in Biological System: Nickel and Its Role in Biology, vol. 23, Marcel Dekker, New York, NY, USA, 1988.

[4] H. Needleman, "Lead poisoning," Annual Review of Medicine, vol. 55, pp. 209-222, 2004.

[5] L. Chandran and R. Cataldo, "Lead poisoning: basics and new developments," Pediatrics in Review, vol. 31, no. 10, pp. 399-406, 2010.

[6] J. A. Staessen, H. A. Roels, D. Emelianov et al., "Environmental exposure to cadmium, forearm bone density, and risk of fractures: prospective population study," The Lancet, vol. 353, no. 9159, pp. 1140-1144, 1999. 
[7] I. Tapsoba, S. Arbault, P. Walter, and C. Amatore, "Finding out Egyptian Gods' secret using analytical chemistry: biomedical properties of Egyptian black makeup revealed by amperometry at single cells," Analytical Chemistry, vol. 82, no. 2, pp. 457-460, 2010.

[8] D. Swandulla and C. M. Armstrong, "Calcium channel block by cadmium in chicken sensory neurons," Proceedings of the National Academy of Sciences of the United States of America, vol. 86, no. 5, pp. 1736-1740, 1989.

[9] H. M. Kim, M. S. Seo, M. J. An et al., “Two-photon fluorescent probes for intracellular free zinc ions in living tissue," Angewandte Chemie International Edition, vol. 47, no. 28, pp. 51675170, 2008.

[10] M. M. Martin, P. Plaza, Y. H. Meyer et al., "Steady-state and picosecond spectroscopy of $\mathrm{Li}^{+}$or $\mathrm{Ca}^{2+}$ complexes with a crowned merocyanine. Reversible photorelease of cations," The Journal of Physical Chemistry, vol. 100, no. 17, pp. 6879-6888, 1996.

[11] C. Amatore, D. Genovese, E. Maisonhaute, N. Raouafi, and B. Schöllhorn, "Electrochemically driven release of picomole amounts of calcium ions with temporal and spatial resolution," Angewandte Chemie, vol. 47, no. 28, pp. 5211-5214, 2008.

[12] A. J. Pearson and J.-J. Hwang, "Crown-annelated P-phenylenediamine derivatives as electrochemical and fluorescenceresponsive chemosensors: Cyclic voltammetry studies," Tetrahedron Letters, vol. 42, no. 21, pp. 3541-3543, 2001.

[13] J. W. Sibert, P. B. Forshee, and V. Lynch, "Wurster's thiacrown ethers: synthesis, properties, and $\mathrm{Pt}(\mathrm{II})$-coordination chemistry," Inorganic Chemistry, vol. 44, no. 23, pp. 8602-8609, 2005.

[14] J. W. Sibert, P. B. Forshee, and V. Lynch, "Electron transfer vs coordination chemistry: isomer-specific binding of $\mathrm{HgII}$ by an ortho-Wurster's thiacrown ether," Inorganic Chemistry, vol. 45, no. 16, pp. 6108-6110, 2006.

[15] R. Sahli, N. Raouafi, E. Maisonhaute, K. Boujlel, and B. Schöllhorn, "Thiophene-based electrochemically active probes for selective calcium detection," Electrochimica Acta, vol. 63, pp. 228-231, 2012.

[16] R. Sahli, N. Raouafi, K. Boujlel, E. Maisonhaute, B. Schöllhorn, and C. Amatore, "Electrochemically active phenylenediamine probes for transition metal cation detection," New Journal of Chemistry, vol. 35, no. 3, pp. 709-715, 2011.

[17] K. X. Bhattacharyya, L. Boubekeur-Lecaque, I. Tapsoba, E. Maisonhaute, B. Schöllhorn, and C. Amatore, "An organometallic derivative of a BAPTA ligand: towards electrochemically controlled cation release in biocompatible media," Chemical Communications, vol. 47, no. 18, pp. 5199-5201, 2011.

[18] D. J. Pirson and P. L. Huyskens, "Specific solvent effects on the complexation of anions by ligands," Journal of Solution Chemistry, vol. 3, no. 7, pp. 503-514, 1974.

[19] J. F. Coetzee and W. R. Sharpe, "Solute-solvent interactions. VII. Proton magnetic resonance and infrared study of ion solvation in dipolar aprotic solvents," Journal of Solution Chemistry, vol. 1, no. 1, pp. 77-91, 1972.

[20] X.-J. Wang, L. Wang, J.-J. Wang, and T. Chen, "Solvent effects on electrochemical behavior of poly(ferrocenylsilane) films," Electrochimica Acta, vol. 52, no. 12, pp. 3941-3949, 2007.

[21] H. Fernández and M. A. Zón, "Solvent effects on the kinetics of heterogeneous electron transfer processes. The TMPD/TMPD. ${ }^{+}$ redox couple," Journal of Electroanalytical Chemistry, vol. 332, no. 1-2, pp. 237-255, 1992.
[22] F. M. Marken, A. Neudeck, and A. M. Bond, Electroanalytical Methods: Guide to Experiments and Applications, Springer, Berlin, Germany, 2010.

[23] J. E. B. Randles, "A cathode ray polarograph. Part II.-The current-voltage curves," Transactions of the Faraday Society, vol. 44, pp. 327-338, 1948.

[24] J. S. Long, D. S. Silvester, A. S. Barnes et al., "Oxidation of several p-phenylenediamines in room temperature ionic liquids: estimation of transport and electrode kinetic parameters," The Journal of Physical Chemistry C, vol. 112, no. 17, pp. 6993-7000, 2008.

[25] N. G. Tsierkezos, "Cyclic voltammetric studies of ferrocene in nonaqueous solvents in the temperature range from 248.15 to 298.15 K," Journal of Solution Chemistry, vol. 36, no. 3, pp. 289302, 2007.

[26] D. W. Hall and C. D. Russell, "Substituent effects in the chronopotentiometric oxidation of ferrocene derivatives. Internal solvation of certain substituted ferricenium ions," Journal of the American Chemical Society, vol. 89, no. 10, pp. 2316-2322, 1967.

[27] G. Gritzner and J. Kuta, "Recommendations on reporting electrode potentials in nonaqueous solvents," Pure and Applied Chemistry, vol. 54, pp. 1527-1532, 1982.

[28] R. G. Compton and C. E. Banks, Understanding Voltammetry, World Scientific, London, UK, 2007.

[29] B. Demirboğa and A. M. Önal, "Electrochemical polymerization of furan and 2-methylfuran," Synthetic Metals, vol. 99, no. 3, pp. 237-242, 1999.

[30] M. Ates, "Electrochemical impedance spectroscopic study of electrocoated polythiophene and poly(2-methyl thiophene) on carbon fiber microelectrode for microcapacitor," International Journal of Electrochemical Science, vol. 4, no. 7, pp. 980-992, 2009.

[31] E. Raamat, K. Kaupmees, G. Ovsjannikov et al., "Acidities of strong neutral Brønsted acids in different media," Journal of Physical Organic Chemistry, vol. 26, no. 2, pp. 162-170, 2012.

[32] A. S. Khamidullina, I. V. Vakulin, R. F. Talipov, and I. S. Shepelevich, "Structure effects of the protonated lincomycin molecule on the mechanism of its complexation with organic compounds," Journal of Structural Chemistry, vol. 46, no. 6, pp. 985-990, 2005.

[33] G. Chaka and A. Bakac, "Two-electron oxidation of $N, N, N$ ', $N^{\prime}$-tetramethylphenylenediamine with a chromium(v) salen complex," Dalton Transactions, no. 2, pp. 318-321, 2009.

[34] S. M. A. Jorge and N. R. Stradiotto, "Complexation studies of $\mathrm{Sn}$ (II) by N,N-dimethylformamide and free energy of transfer of $\mathrm{Sn}(\mathrm{II})$ from acetonitrile to N,N-dimethylformamide," Analytica Chimica Acta, vol. 242, no. 2, pp. 295-298, 1991.

[35] P. D. Beer, P. A. Gale, and G. Z. Chen, "Mechanisms of electrochemical recognition of cations, anions and neutral guest species by redox-active receptor molecules," Coordination Chemistry Reviews, vol. 185-186, pp. 3-36, 1999.

[36] J.-M. Savéant, Elements of Molecular and Biomolecular Electrochemistry: An Electrochemical Approach to Electron Transfer Chemistry, John Wiley \& Sons, Hoboken, NJ, USA, 2006.

[37] P. D. Beer, P. A. Gale, and Z. Chen, "Electrochemical Recognition of charged and neutral guest species by redox-active Receptor Molecules," Advances in Physical Organic Chemistry, vol. 31, pp. 1-90, 1999.

[38] V. S. Elanchezhian and M. Kandaswamy, "A ferrocene-based multi-signaling sensor molecule functions as a molecular 
switch," Inorganic Chemistry Communications, vol. 12, no. 2, pp. 161-165, 2009.

[39] M. Alfonso, A. Tárraga, and P. Molina, "Ferrocene-based multichannel molecular chemosensors with high selectivity and sensitivity for $\mathrm{Pb}(\mathrm{II})$ and $\mathrm{Hg}(\mathrm{II})$ metal cations," Dalton Transactions, vol. 39, no. 37, pp. 8637-8645, 2010.

[40] P. Molina, A. Tárraga, and A. Caballero, "Ferrocene-based small molecules for multichannel molecular recognition of cations and anions," European Journal of Inorganic Chemistry, no. 22, pp. 3401-3417, 2008. 

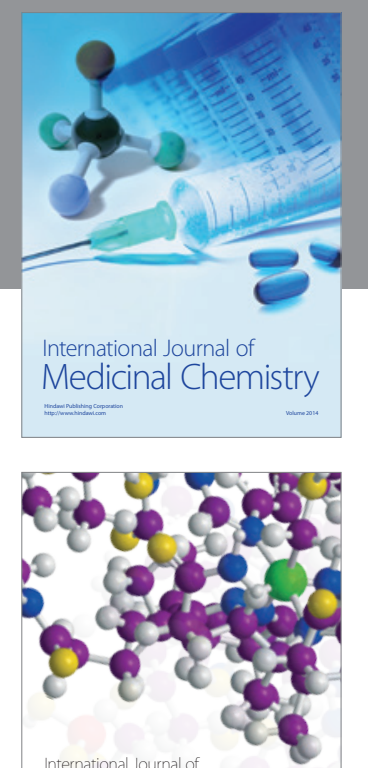

\section{Carbohydrate} Chemistry

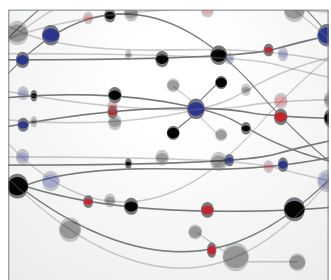

The Scientific World Journal
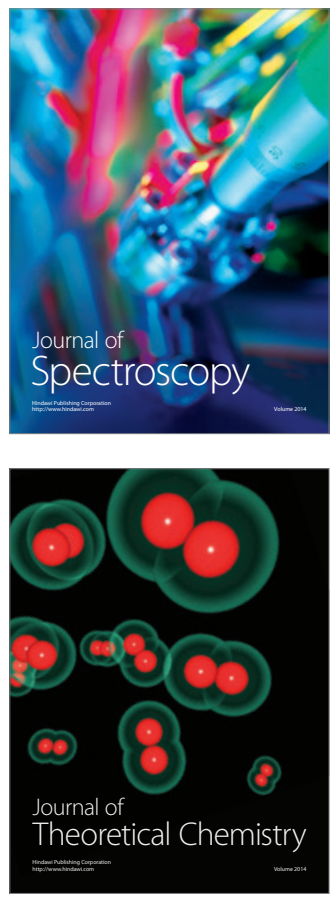
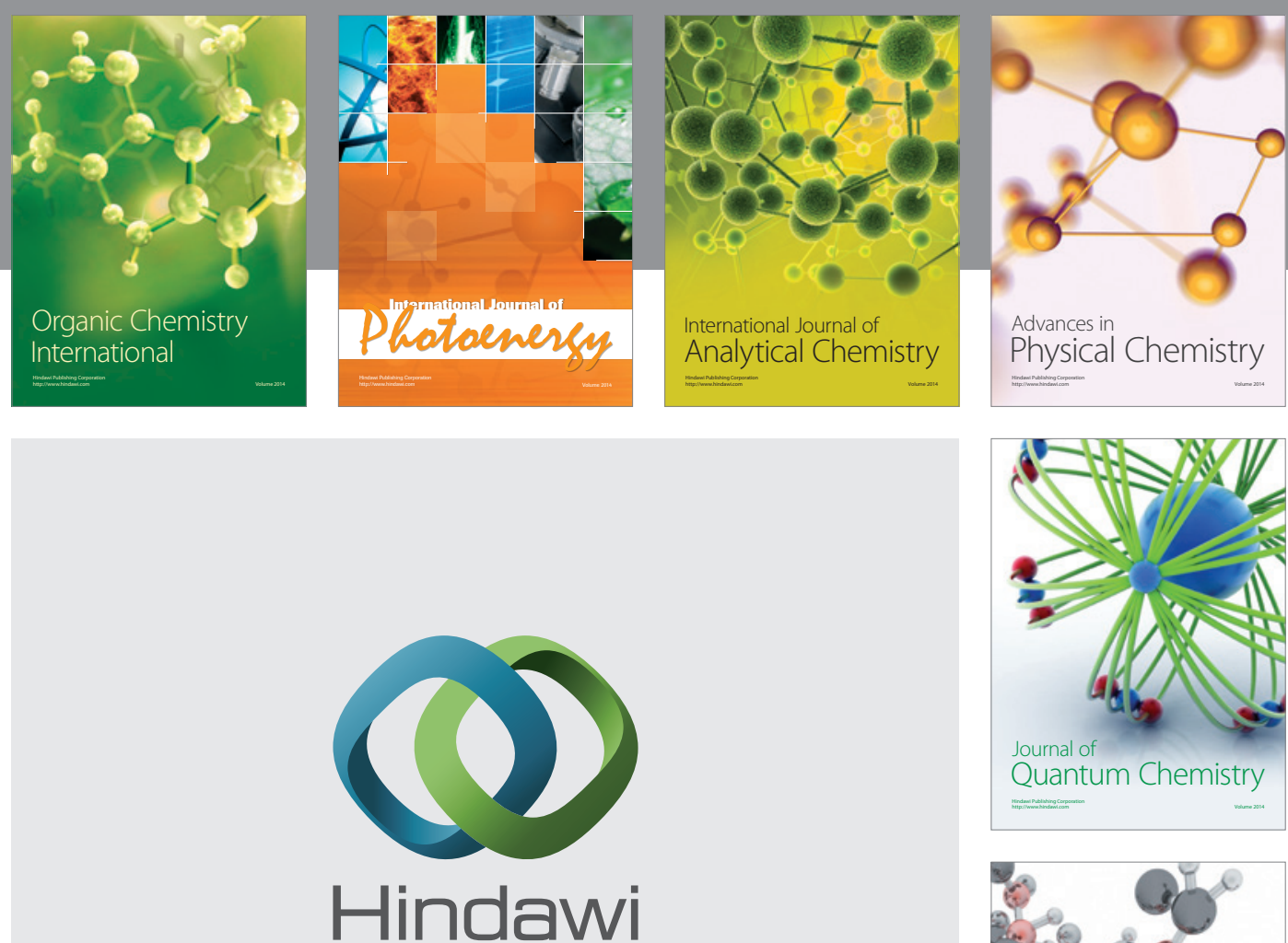

Submit your manuscripts at

http://www.hindawi.com

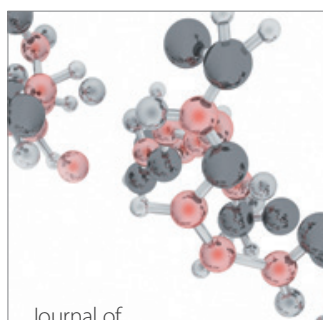

Analytical Methods

in Chemistry

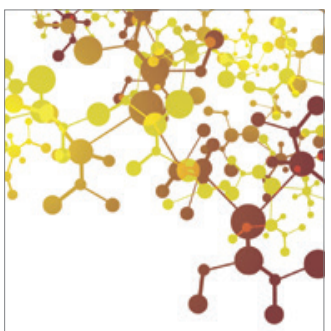

Journal of

Applied Chemistry

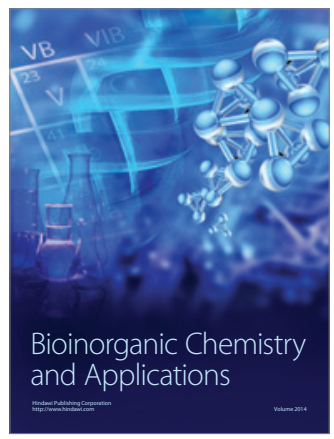

Inorganic Chemistry
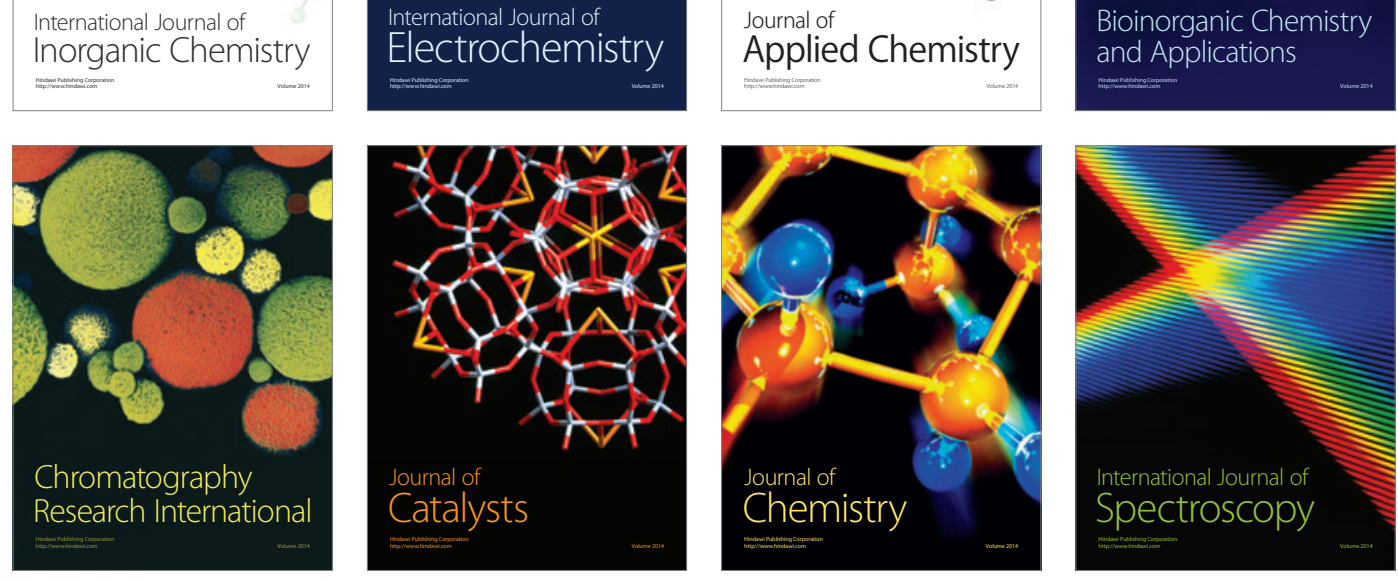